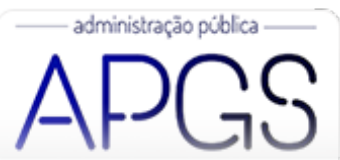

Administração Pública e Gestão Social ISSN: 2175-5787

apgs@ufv.br

Universidade Federal de Viçosa

Brasil

\title{
Identificação Organizacional Cooperativa: a influência de um Novo Construto sobre o Clima Organizacional
}

dos Santos Bento, Marcia Helena; da Rosa Gama Madruga, Lucia Rejane; Peixoto Stecca, Jaime; de Fátima Barros Estivalete, Vania

Identificação Organizacional Cooperativa: a influência de um Novo Construto sobre o Clima Organizacional Administração Pública e Gestão Social, vol. 14, núm. 1, 2022

Universidade Federal de Viçosa, Brasil

Disponible en: https://www.redalyc.org/articulo.oa?id=351569604008

\section{(c) (1) $\Theta(9$}

Esta obra está bajo una Licencia Creative Commons Atribución-NoComercial-SinDerivar 4.0 Internacional. 
Identificação Organizacional Cooperativa: a influência de um Novo Construto sobre o Clima Organizacional

Cooperative Organizational Identification: the influence of a New Construct on the Organizational Climate Identificación organizacional cooperativa: la influencia de un nuevo concepto en el clima organizacional

Marcia Helena dos Santos Bento

Universidade Federal de Santa Maria, Brasil

Redalyc: https://www.redalyc.org/articulo.oa?

marciabento@politecnico.ufsm.br

Lucia Rejane da Rosa Gama Madruga

Universidade Federal de Santa Maria, Brasil

luciagm@ufsm.br

Jaime Peixoto Stecca

Universidade Federal de Santa Maria, Brasil

jaime@politecnico.ufsm.br

Vania de Fátima Barros Estivalete

Universidade Federal de Santa Maria, Brasil

vaniaestivalete@ufsm.br

Recepción: 19 Abril 2021

Aprobación: 26 Agosto 2021

Publicación: 08 Enero 2022

\section{Resumo:}

Objetivo da pesquisa: Analisar a influência da identificação organizacional cooperativa sobre o clima organizacional.

Enquadramento teórico: Teoria da Identidade Organizacional (Ashforth \& Mael, 1989).

Metodologia: Foi realizada uma survey a partir de uma escala de Identificação Organizacional, construída especificamente para as cooperativas, juntamente com uma escala reduzida de clima organizacional adaptada transculturalmente para as cooperativas. A análise dos dados foi realizada com abordagem quantitativa, utilizando as técnicas de análise fatorial exploratória e confirmatória. Resultados: A análise de caminhos estruturais revelou que o construto 'Ajuste ao Grupo' é o que mais influencia o Clima Organizacional. O modelo final validado combinou um construto de segunda ordem, quatro construtos de primeira ordem e 17 variáveis. Os resultados finais do modelo demonstraram que o Clima Organizacional é 83,7\% explicado por seus aspectos Afetivo, Cognitivo e Instrumental.

Originalidade: As cooperativas possuem diversas características que as diferenciam de sociedades convencionais e, por isso, necessitam de construtos teóricos adequados a sua realidade. As características diferenciadoras das cooperativas são autodeclaradas mundialmente, mas não foram estudadas a partir da Teoria da Identidade Organizacional.

Contribuições teóricas e práticas: A presente pesquisa desenvolve um novo construto e escala denominados Identidade Organizacional Cooperativa. A escala de Clima Organizacional foi traduzida e adaptada transculturalmente para a realidade das cooperativas brasileiras.

Palavras-Chave: Identidade Organizacional, Identificação Organizacional, Clima Organizacional, Cooperativas, Cooperativas de Crédito.

\section{Abstract:}

Purpose of the research: To analyze the influence of cooperative organizational identification on the organizational climate. Theoretical framework: Theory of Organizational Identity (Ashforth \& Mael, 1989)

Methodology: A survey was carried out from an Organizational Identification scale built specifically for cooperatives together with a reduced scale of organizational climate adapted cross-culturally for cooperatives. Data analysis was performed using a quantitative approach, using the techniques of exploratory and confirmatory factor analysis. 
Results: The analysis of structural paths revealed that the 'Group Adjustment' construct is the one that most influences the Organizational Climate. The final validated model combined a second order construct, 4 first order constructs and 17 variables. The final results of the model demonstrated that the Organizational Climate is $83.7 \%$ explained by its Affective, Cognitive and Instrumental aspects.

Originality: Cooperatives have several characteristics that differentiate them from conventional societies, and therefore they need theoretical constructs adapted to their reality. The differentiating characteristics of cooperatives are self-declared worldwide, but they have not been studied from the Theory of Organizational Identity.

Theoretical and practical contributions: This research develops a new construct and scale called Cooperative Organizational Identity. The Organizational Climate scale was translated and cross-culturally adapted to the reality of Brazilian cooperatives.

KEYWORDS: Organizational Identity, Organizational Identification, Organizational Climate, Cooperatives, Credit Unions.

\section{RESUMEN:}

Objeto de la investigación: Analizar la influencia de la identificación organizacional cooperativa en el clima organizacional. Marco teórico: Teoría de la identidad organizacional (Ashforth \& Mael, 1989)

Metodología: Se realizó una encuesta a partir de una escala de Identificación Organizacional construida específicamente para cooperativas junto con una escala reducida de clima organizacional adaptado transculturalmente para las cooperativas. El análisis de los datos se realizó mediante un enfoque cuantitativo, utilizando las técnicas de análisis factorial exploratorio y confirmatorio. Resultados: El análisis de trayectorias estructurales reveló que el constructo 'Ajuste de grupo' es el que más influye en el Clima Organizacional. El modelo final validado combinó una construcción de segundo orden, 4 construcciones de primer orden y 17 variables. Los resultados finales del modelo demostraron que el Clima Organizacional se explica en un 83,7\% por sus aspectos Afectivo, Cognitivo e Instrumental.

Originalidad: Las cooperativas tienen varias características que las diferencian de las sociedades convencionales, por lo que necesitan construcciones teóricas adaptadas a su realidad. Las características diferenciadoras de las cooperativas se autodeclaran a nivel mundial, pero no han sido estudiadas desde la Teoría de la Identidad Organizacional.

Contribuciones teóricas y prácticas: Esta investigación desarrolla un nuevo constructo y escala denominada Identidad Organizacional Cooperativa. La escala de Clima Organizacional fue traducida y adaptada transculturalmente a la realidad de las cooperativas brasileñas.

Palabras ClaVE: Identidad organizacional, Identificación organizacional, Clima organizacional, Cooperativas, Las cooperativas de crédito.

\section{INTRODUÇÃo}

As pessoas possuem características, positivas e negativas, que as diferenciam entre si, assim como as organizações são diferenciadas a partir de determinadas características. Esse conjunto de características é o que formará a identidade de uma organização que pode ser uma forma de antever o seu comportamento diante de determinadas situações (Kogut \& Zander, 1996). Ou seja, ao conhecer a identidade de uma empresa, pode-se prever o comportamento de uma organização em relação às mais diversas situações apresentadas pelo ambiente. Ao focar a pesquisa à nível de colaboradores, faz-se necessário utilizar o construto de identificação organizacional, pois, a identidade é da organização.

As cooperativas possuem uma identidade que as diferencia de sociedades convencionais, atuando nas mais diversas atividades, e o único tipo de empresa que possui um código de ética com valores internacionalmente acordado (Internacional Co-operative Alliance, 2017). Durante o congresso centenário da Aliança Cooperativa Internacional (ACI), em Manchester, ocorrido em 1995, foram consagradas as principais características da sociedade cooperativa: adesão voluntária e livre; gestão democrática pelos membros; participação econômica dos membros; autonomia e independência; educação, formação e informação; intercooperação; e, interesse pela comunidade (Paré, 2009). No entanto, conforme pesquisas em periódicos (Web Of Sciece e Capes), existe uma lacuna para estudos envolvendo o construto de identificação organizacional em cooperativas, justificando a utilização desse construto na pesquisa.

O segundo construto utilizado, Clima Organizacional, pode ser utilizado de forma estratégica por algumas organizações, apoiando-se na construção de ambientes de trabalho propícios para a diferenciação desejada. 
Um exemplo de modificação no ambiente de trabalho focado em estratégia é a pesquisa de Klein e Sorra (1996), que buscou criar um clima organizacional favorável à implementação de inovações, a partir do qual, os colaboradores que utilizassem as inovações eram recompensados.

Um clima organizacional favorável é benéfico para clientes, colaboradores e empresa, assim como um clima desfavorável traz prejuízos como improdutividade, alta abstenção, clientes insatisfeitos, entre outros (Bispo, 2006). Se algumas organizaçóes utilizam o clima organizacional para elaborar estratégias que as diferenciem em seu nicho de mercado (Klein \& Sorra, 1996), talvez a identidade organizacional, formada por elementos diferenciadores, possa influenciar seu ambiente de trabalho estrategicamente por meio da identificação dos colaboradores com a organização.

O ramo de crédito do cooperativismo é um dos ramos mais dinâmicos do cooperativismo, pois, busca-se a melhor administração dos recursos financeiros dos cooperados. As cooperativas de crédito atendem cerca de 1,9 milhão de associados no Rio Grande do Sul, em que todos os correntistas são associados e geram em torno de 9,9 mil empregos diretos (OCERGS-SESCOOP/RS, 2017), pautando a escolha de três cooperativas de crédito do Rio Grande do Sul como objeto de estudo.

A partir do Plano de Ação para uma Década Cooperativa, que coloca a Identidade como tema central; considerando a importância da percepção da Identidade Cooperativa pelos colaboradores; e, ainda, analisando trabalhos que objetivaram diagnosticar o clima organizacional de cooperativas (Parolin \& Albuquerque, 2011; STECCA et al., 2016;), chegou-se à seguinte questão de pesquisa: De que forma a Identificação Organizacional Cooperativa influencia o Clima Organizacional dos colaboradores de Cooperativas de Crédito?

Para responder a esse questionamento, apresenta-se como objetivo geral analisar a influência da identificação organizacional cooperativa sobre o clima organizacional. Os objetivos específicos do estudo consistem em: (i) elaborar e validar uma escala de identificação organizacional cooperativa; (ii) traduzir, adaptar culturalmente e validar a escala de percepção de clima organizacional; (iii) analisar a influência da identificação organizacional cooperativa sobre o clima organizacional.

O estudo é apresentado em, basicamente, quatro partes: referencial teórico, expondo os construtos de identidade organizacional cooperativa, identificação organizacional cooperativa e clima organizacional; procedimentos metodológicos, apresentação e discussão dos resultados; e considerações finais.

\section{IDENTIDADE ORGANIZACIONAL COOPERATIVA: CONTRIBUIÇÕES PARA A FORMAÇÃO DO CONSTRUTO IDENTIFICAÇÃO PARA O CONTEXTO DO COOPERATIVISMO}

A Identidade Organizacional é uma forma específica de Identidade Social, autodefinida ou autodeclarada (Mael \& Asforth, 1992), e distinta de outras organizações por meio de características diferenciadoras (Kogut \& Zander, 1996). A Declaração sobre Identidade, Valores e Princípios Cooperativistas é a autodefinição realizada pela Internacional Co-operative Alliance para distinguir as cooperativas de outras formas societárias (International Co-operative Alliance, 2015).

Embora a Declaração seja composta pela definição de cooperativa, pelos valores básicos e éticos e pelos princípios do cooperativismo, observou-se que a essência do cooperativismo se encontra nos valores. Os princípios, amplamente definidos e conhecidos, representam a aplicação dos valores no dia a dia das cooperativas. Ao buscar a base das características diferenciadoras, constatou-se que os valores básicos do cooperativismo desempenhavam essa função (Schneider, 2012; International Co-operative Alliance, 2015).

Essa necessidade de distinguir as cooperativas de outras empresas é tão antiga quanto o próprio cooperativismo, embora tenha sido formalizada de forma global apenas em 1995(Internacional Co-operative Alliance, 2017). A fim de definir uma Identidade Organizacional intrínseca às cooperativas, elaborou-se um quadro de referência da Identidade Organizacional Cooperativa demonstrando essa associação. Dessa forma, 
o Quadro 1 resumiu o caminho percorrido da Identidade Organizacional até a formação da Identidade Organizacional Cooperativa.

Quadro 1: Quadro referência da Identidade Organizacional Cooperativa

\begin{tabular}{|c|c|c|c|}
\hline $\begin{array}{l}\text { IDENTIDADE } \\
\text { ORGANIZACIONAL }\end{array}$ & $\begin{array}{c}\text { Forma especifica de Identidade Social } \\
\text { autodefinida ou autodeclarada } \\
\text { (Mael \& Asforth, 1992) }\end{array}$ & $\begin{array}{l}\text { Declaração sobre a } \\
\text { Identidade, Valores e } \\
\text { Princinios }\end{array}$ & \\
\hline \multicolumn{2}{|l|}{$\begin{array}{l}\text { Características diferenciadoras } \\
\text { (Kogut \& Zander, 1996) }\end{array}$} & (ICA, 2015) & \\
\hline \multicolumn{2}{|c|}{ Caracteristicas diferenciadoras das sociedades cooperativas (Pinho, 1966, p.53) } & Valores Básicos (ICA, 2015) & \\
\hline \multicolumn{2}{|c|}{ É uma sociedade de pessoas. } & Equidade, Autoajuda & \\
\hline \multicolumn{2}{|c|}{ Objetivo principal é a prestação de serviço. Não tem lucro, mas sim sobras. } & Solidariedade, Autoajuda & \\
\hline \multicolumn{2}{|c|}{ Número ilimitado de cooperados (adesão livre). } & Autoajuda, Democracia & 事 \\
\hline \multicolumn{2}{|c|}{ Controle democrático: um homem, um voto. } & Democracia, Autoajuda & 송 \\
\hline \multicolumn{2}{|c|}{ Assembleia: quórum com base no número de cooperados. } & Igualdade, Responsabilidade & द्र \\
\hline \multicolumn{2}{|c|}{$\begin{array}{l}\text { Não é permitida a transferência das quotas-partes a terceiros estranhos à } \\
\text { sociedade. }\end{array}$} & bilidade & 自皆 \\
\hline Retorno proporcional ao valor $\mathrm{da}$ & Šes (retorno aos cooperados). & Equidade & \\
\hline
\end{tabular}

Fonte: Elaborado pelos autores.

De acordo com o Quadro 1, a Identidade Organizacional precisa atender a dois requisitos: ter características diferenciadoras e uma forma específica de identidade autodefinida. No cooperativismo, a autora Pinho (1966) relacionou o que diferencia, na prática, as sociedades cooperativas das demais sociedades, assim como a Internacional Cooperative Alliance (2015), organismo recoconhecido mundialmente, adotou a Declaração sobre a Identidade, Valores e Princípios desde 1995 como uma forma de autodefinção da identidade cooperativa.

A Declaração sobre a Identidade, Valores e Princípios (2015) apenas cita esses valores, o que tem instigado diversos autores a elucidar da melhor forma sua aplicação nas cooperativas. A seguir, conceituam-se os valores abordados no Quadro 1:

- Autoajuda: O valor de autoajuda pressupõe a autonomia das pessoas e das cooperativas, a ação de seus membros em busca de seu desenvolvimento e de seus semelhantes, significa o orgulho do cooperado, que garante a liberdade de suas ações, principalmente, em relação ao governo e grandes clientes e/ou fornecedores (Lambert, 1975; Souza, 2017).

- Responsabilidade: O valor de responsabilidade está relacionado ao comprometimento com as atividades e cumprimento dos deveres, em ter atitudes responsáveis a fim de não lesar as partes interessadas, em responder pelas decisões e em acompanhar a vida da cooperativa. Nesse valor pressupõe-se, ainda, os valores éticos de retidão moral e respeito às normas coletivas. A divulgação e a disseminação do cooperativismo também estão inseridas como exemplos do valor responsabilidade no meio cooperativista (Figueiredo, 2009; Mêinen, 2014; Souza, 2017).

- Democracia: A democracia, nas cooperativas, está vinculada ao direito de participação pela palavra e pelo voto, incluindo reunióes e o exercício de funçóes diretivas, bem como ao dever de respeitar as deliberações realizadas nessa forma (Rossi, 2005; Mêinen, 2014). Implica também, no direito de manifestação de opinião, de compreensão e de respeito às divergências e diferenças, ao estímulo à argumentação e à tomada de decisões em comum acordo ou pela maioria (Rossi, 2005; Souza, 2017).

- Igualdade e Equidade: Os valores de igualdade e equidade caminham juntos, em busca da igualdade de direitos de participação, informação e comunicação, muitas vezes sendo necessária a compensação do esforço de cada um, promovendo julgamento justo e imparcial (Mêinen, 2014; Souza, 2017).

- Solidariedade e Ajuda Mútua: É um valor de empatia, de se responsabilizar pelo outro como se fosse consigo, é não ser individualista, mas focar na união de esforços em prol de um objetivo 
comum, implica em reciprocidade obrigacional, responsabilizando-se em conjunto pelo exercício das atividades necessárias ao alcance desse objetivo (Rossi, 2005; Mêinen, 2014; Souza, 2017).

Assim, observou-se a interligação de, pelo menos, um valor básico a uma característica diferenciadora das sociedades cooperativas, formando a Identidade Organizacional Cooperativa (IdCoop). Com a IdCoop definida, a próxima etapa foi a caracterização da Identificação Organizacional Cooperativa.

\section{IdentificaÇão Organizacional Cooperativa}

O construto de Identificação Organizacional Cooperativa foi elaborado a partir da Teoria da Identidade Organizacional (Ashforth \& Mael, 1989) e da Declaração sobre a Identidade, Valores e Princípios do Cooperativismo (International Co-operative Alliance, 2015).

O primeiro passo foi a formação da Identidade Organizacional Cooperativa, contemplando as características diferenciadoras (Pinho, 1966; Kogut \& Zander, 1996) e a autodefinição de identidade (Mael \& Ashforth, 1992; International Co-Operative Alliance, 2015). Estabelecida a composição da Identidade Organizacional Cooperativa pelos valores básicos do cooperativismo, agrupados em cinco definições, deu-se a continuidade da formação do construto de identificação.

Por meio dos conceitos-chave encontrados para os valores, foram redefinidas a interpretação dos valores básicos do cooperativismo para a óptica dos colaboradores. Essa adaptação foi necessária para avaliar a identificação, devido ao fato de os valores do cooperativismo pertencerem à identidade cooperativa.

A escala utilizada incluiu itens elaborados a partir dos construtos de Identificação Organizacional Cooperativa, buscando contemplar as dimensóes Afetiva e Cognitiva da Identificação Organizacional Cooperativa e as dimensões de Autoajuda, Democracia, Igualdade e Equidade, Responsabilidade, e Solidariedade e Ajuda Mútua. O Quadro 2 apresenta um resumo do construto.

Quadro 2: Construto de Identificação Organizacional Cooperativa

\begin{tabular}{|c|c|c|}
\hline \multicolumn{2}{|c|}{ CONSTRUTOS } & ASPECTOS NORTEADORES \\
\hline \multirow{5}{*}{ 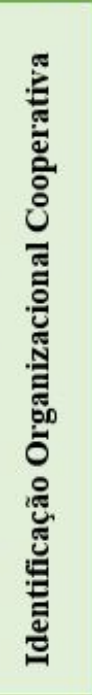 } & Autoajuda & $\begin{array}{l}\text { Implica no desenvolvimento dos colaboradores, por meio de educação formal e/ou } \\
\text { informal, sobre a cultura cooperativa, bem como a formação integral do cidadão, } \\
\text { possibilitando aos colaboradores maior autonomia e melhor desempenho de suas } \\
\text { atividades na cooperativa. }\end{array}$ \\
\hline & Democracia & $\begin{array}{l}\text { É visualizada na participação das decisões, na livre manifestação de sua opinião e no } \\
\text { respeito pelas decisões tomadas pela maioria. }\end{array}$ \\
\hline & $\begin{array}{l}\text { Igualdade e } \\
\text { Equidade }\end{array}$ & $\begin{array}{l}\text { Podem ser observadas no tratamento sem distinção dispensado aos colaboradores, no } \\
\text { direito à participação nas decisões de seu setor, bem como na disponibilização de } \\
\text { oportunidades iguais de crescimento dentro da cooperativa. }\end{array}$ \\
\hline & $\begin{array}{l}\text { Responsa- } \\
\text { bilidade }\end{array}$ & $\begin{array}{l}\text { Significa ter uma postura responsável, sem prejudicar os colegas de trabalho, se } \\
\text { comprometendo com as tarefas a serem realizadas e com o sucesso da cooperativa. } \\
\text { Implica, também, em ter valores éticos de retidão moral e respeito às normas } \\
\text { coletivas. Ainda pode ser desejável a divulgação e a disseminação do cooperativismo } \\
\text { entre amigos e familiares, como forma de perpetuação dos preceitos cooperativistas. }\end{array}$ \\
\hline & $\begin{array}{l}\text { Solidariedade } \\
\text { e Ajuda mútua }\end{array}$ & $\begin{array}{l}\text { Se manifesta no apoio mútuo entre colegas, um contribuindo com o outro em prol do } \\
\text { desenvolvimento do trabalho. É a satisfação em ajudar e a certeza de poder contar } \\
\text { com a ajuda dos colegas nos compromissos organizacionais. }\end{array}$ \\
\hline \multirow{2}{*}{ 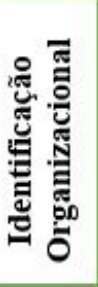 } & Afetiva & $\begin{array}{l}\text { Buscam o autoaprimoramento (motivação para se conectar emocionalmente com o } \\
\text { ambiente social). Está relacionada a variáveis do processo de grupo, como coesão, } \\
\text { comunicação, flexibilidade e conflito. Predispõe os indivíduos ao afeto positivo. }\end{array}$ \\
\hline & Cognitiva & $\begin{array}{l}\text { Buscam a certeza (motivação epistemica para entender o ambiente social de uma } \\
\text { pessoa). Se preocupam com seu comportamento em situações sociais. A } \\
\text { identificação com um grupo social reduz a incerteza das situações sociais, pois o } \\
\text { grupo prescreve o comportamento apropriado. }\end{array}$ \\
\hline
\end{tabular}


Fonte: Elaborado pelos autores.

A fim de complementar a análise da identificação organizacional cooperativa, foi analisado se o novo construto de identificação influencia no clima. O clima organizacional, construído e sustentado por relações interpessoais, tem sua importância na medida em que orienta o comportamento e o desempenho dos indivíduos dentro das organizações (Puente-Palacios \& Freitas, 2006). Portanto, a próxima seção aborda o aporte teórico sobre Clima Organizacional.

\section{Clima Organizacional}

A compreensão da forma como o ambiente de trabalho afeta o comportamento e as atitudes das pessoas, tem-se dado por meio do Clima Organizacional, que busca conhecer as percepções compartilhadas entre as pessoas de uma organização ou equipes de trabalho (Martins, 2008). O Clima Organizacional nada mais é do que a soma de fatores que influenciam o dia a dia das pessoas, como o relacionamento com os pares, com os superiores, as condições físicas e psicológicas do trabalho, entre outros (Johann, 2013). Assim, buscou-se na literatura internacional uma escala que representasse os principais fatores de clima.

A versão reduzida da escala CLIOR, contendo 15 itens que representam seis construtos, fornece um indicador geral de clima organizacional e é composta por indicadores de cooperação, organização do trabalho, relacionamento, inovação, participação e apego ao trabalho (Peña-Suárez et al., 2013). A descrição desses construtos é dada a seguir, conforme Menéndez et al. (2017):

- Cooperação: o nível de apoio dado por colegas e superiores possui motivo e o significado é compreendido.

- Organização do trabalho: representa a importância que a organização atribui às regras e procedimentos; até que ponto a empresa controla os aspectos organizacionais de cada posto para garantir que esses objetivos sejam claros e transparentes.

- Relacionamentos: mede a percepção dos funcionários sobre o ambiente de trabalho e se eles sentem, ou não, que trabalham dentro de um ambiente agradável com interações positivas, em sentido horizontal (com colegas) ou vertical (chefes e superiores).

- Inovação: refere-se ao grau de inovação, dinamismo e adaptação da empresa às exigências atuais

- Participação: mostra o grau de liberdade que a empresa oferece aos funcionários para sugerir novas ideias e procedimentos que possam melhorar os níveis de desempenho.

- Identificação: refere-se ao sentimento de satisfação e à sensação de realização e orgulho associados ao trabalho.

\section{Procedimentos Metodológicos}

O estudo realizado foi de levantamento ou do tipo survey, de corte transversal, ou seja, realizado em apenas um ponto do tempo e sintetizados estatisticamente (Hair et al., 2005) com abordagem quantitativa sobre dados primários oriundos de questionários.

A pesquisa teve como objeto de estudo os colaboradores e gerentes de gestão de pessoas que atuam nas cooperativas de crédito Sicredi Região Centro RS/MG, Sicredi Serrana RS e Sicredi União RS. A escolha dessas cooperativas se justifica por empregar 1.408 colaboradores, em 80 municípios do Rio Grande do Sul.

A distribuição desses 1.408 colaboradores e três gerentes de gestão de pessoas, podem ser observados na Tabela 1. Esses números compuseram a população-alvo da pesquisa. 
Tabela 1: Número de Colaboradores por Cooperativa

\begin{tabular}{lllllll}
\hline \multirow{2}{*}{ Cooperativa } & \multicolumn{2}{l}{$\mathrm{N}^{\circ}$ de Colaboradores } & \multicolumn{4}{c}{$\begin{array}{l}\text { No de gerentes de gestão } \\
\text { de pessoas }\end{array}$} \\
\cline { 2 - 7 } & Total & Participantes & $\mathbf{\%}$ & Total & Participantes & $\mathbf{\%}$ \\
\hline $\begin{array}{l}\text { Sicredi } \\
\text { Região }\end{array}$ & 328 & 77 & 23,48 & 01 & 01 & 100 \\
$\begin{array}{l}\text { Centro } \\
\text { RS /MG }\end{array}$ & & & & & & \\
$\begin{array}{l}\text { Sicredi } \\
\text { Serrana RS }\end{array}$ & 452 & 130 & 28,76 & 01 & 01 & 100 \\
$\begin{array}{l}\text { Sicredi } \\
\text { União RS }\end{array}$ & 628 & 137 & 21,81 & 01 & 01 & 100 \\
\hline Total & $\mathbf{1 . 4 0 8}$ & $\mathbf{3 4 4}$ & $\mathbf{2 4 , 4 3}$ & $\mathbf{0 3}$ & $\mathbf{0 3}$ & $\mathbf{1 0 0}$ \\
\hline
\end{tabular}

Fonte: Dados da pesquisa.

O cálculo amostral seguiu a recomendação de Hair et al. (2009) para validação do instrumento, que implica em alcançar um número de cinco observações para cada questão a ser validada, sendo a proporção 10x1 desejável. Como o instrumento utilizado possui 21 questões de Identificação Organizacional Cooperativa (IOC) e 15 questões de Clima Organizacional (CO), totalizando 36 questões a serem validadas, eram necessários no mínimo 180 indivíduos.

A amostra foi composta por 185 indivíduos do sexo feminino e 159 do sexo masculino. O teste QuiQuadrado, com nível de confiança de 95\%, não rejeita a hipótese nula de distribuição uniforme (sig=0,161), ou seja, é possível afirmar que a diferença de sexo não é significativa. A média de idade dos respondentes variou de 14 a 62 anos, com média de 33,77 anos e desvio padrão de 7,604. Observou-se, ainda, a concentração na faixa etária dos 30 aos 35 anos, com um percentual de 30,1\% da amostra analisada.

As categorias analíticas utilizadas no presente estudo podem ser observadas no quadro-resumo dos construtos da pesquisa utilizados na construção dos instrumentos e relacionados aos principais autores e dimensões/variáveis analisadas (Quadro 3).

Quadro 3: Construtos Teóricos e Dimensões / Variáveis analisadas

\begin{tabular}{|c|c|c|}
\hline $\begin{array}{l}\text { Construto } \\
\text { Teórico }\end{array}$ & Principais autores & $\begin{array}{l}\text { Dimensões / Variáveis } \\
\text { ( } N^{0} \text { da questão) }\end{array}$ \\
\hline $\begin{array}{l}\text { Identificação } \\
\text { Organizacional } \\
\text { Cooperativa }\end{array}$ & $\begin{array}{l}\text { Johnson, Morgeson } \\
\text { e Hekman (2012) } \\
\text { Hannah et al. } \\
\text { (2014) Kluver, } \\
\text { Frazier e Haidt } \\
\text { (2014) Hakak } \\
\text { (2015) Lambert } \\
\text { (1975) Figueiredo } \\
\text { (2009) ICA (2015) }\end{array}$ & $\begin{array}{l}\text { - Autoajuda (01, 12, 14, } \\
17 \text { e 19) - Democracia } \\
\text { (05, 07 e 15) - Igualdade } \\
\text { e Equidade (03, 08 e 10) } \\
\text { - Responsabilidade (11, } \\
13,16 \text { e 18) - } \\
\text { Solidariedade e Ajuda } \\
\text { mútua (02, 04, 06 e 09) } \\
\text { - Identificação } \\
\text { Organizacional (20 e 21) }\end{array}$ \\
\hline $\begin{array}{l}\text { Clima } \\
\text { Organizacional }\end{array}$ & $\begin{array}{l}\text { Penã-Suárez et al. } \\
\text { (2013) Muñiz et al. } \\
\text { (2014) }\end{array}$ & Unidimensional \\
\hline
\end{tabular}

Fonte: Dados da pesquisa

A primeira parte do instrumento avaliou em 21 questões a Identificação Organizacional Cooperativa a partir dos valores de Autoajuda, Democracia, Igualdade e Equidade, Responsabilidade e, ainda, Solidariedade e Ajuda Mútua. A segunda parte do instrumento, que avaliou o Clima Organizacional, foi utilizada a versão reduzida e unidimensional da Escala de Clima Organizacional de Muñiz et al. (2014), adaptada 
transculturalmente com 15 itens. Os dois construtos utilizaram a escala Likert de 5 pontos, em que o respondente optaria entre 1 para Discordo Totalmente e 5 para Concordo Totalmente. As escalas foram validadas por especialistas e o teste-piloto evidenciou um Alfa de Cronbach $>0,8$ nas duas escalas, demonstrando uma associação muito boa entre os construtos (Hair et al., 2005).

A análise fatorial exploratória foi realizada por meio do software SPSS versão 23, utilizando o método dos componentes principais com extração de fatores com base no autovalor e rotação ortogonal pelo método Varimax. A adequação da amostra foi dada pelo teste KMO (Kaiser-Meyer-Olkin) e a adequação dos dados pelo teste de esfericidade de Bartlett que indicou correlações significativas entre as variáveis. Após a extração dos fatores foi verificada a consistência interna por meio do Alfa de Cronbach. Após a denominação dos fatores pela Análise Fatorial Exploratória (AFE)[i], realizou-se um teste confirmatório por meio da Análise Fatorial Confirmatória (AFC)[ii] e continuou-se a testagem do modelo estrutural por meio da Modelagem de Equações Estruturais (MEE) utilizando o pacote estatístico Amos 21 e selecionando o método de estimação de Máxima Verossimilhança (ML), conforme ilustra a Figura 1.

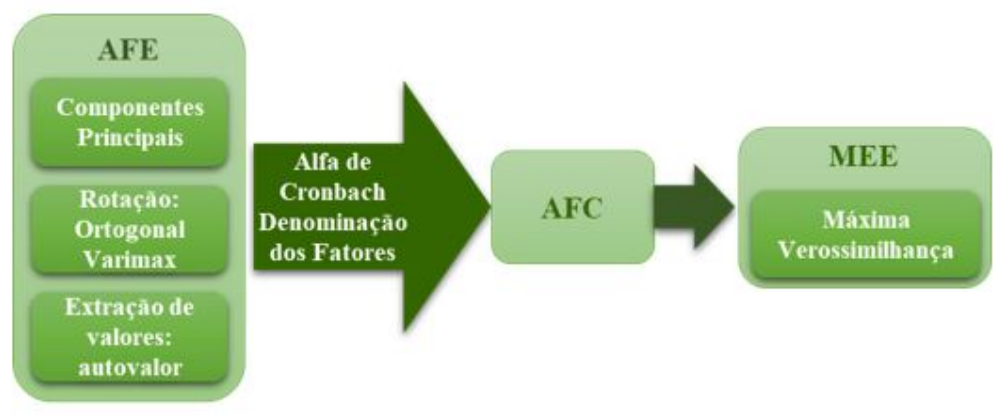

Figura 1: Etapas da Análise dos Dados

Fonte: Elaborado pelos autores.

A validade do modelo de mensuração foi analisada pela qualidade de ajuste do modelo. Foram utilizadas medidas de ajuste absoluto como o Qui-quadrado, Qui-quadrado por Graus de Liberdade, Goodness-offit (GFI), Roat Mean Square Error of Aproximation (RMSEA) e, como medida de ajuste incremental, o Comparative Fit Index (CFI) (Hair et al., 2009).

\section{ApresentaÇão e Discussão dos Resultados}

A apresentação e discussão dos resultados será abordada a partir dos objetivos específicos do estudo: (i) elaborar e validar uma escala de identificação organizacional cooperativa; (ii) traduzir, adaptar culturalmente e validar a escala de percepção de clima organizacional; (iii) analisar a influência da identificação organizacional cooperativa sobre o clima organizacional.

\subsection{Identificação Organizacional Cooperativa - A Percepção dos Pesquisados}

A validação da escala de Identificação Organizacional Cooperativa (IOC) foi realizada pelas análises fatoriais exploratória e confirmatória. A análise fatorial exploratória iniciou pela verificação do teste de esferecidade de Bartlett, que indicou a adequação da análise fatorial com significância < 0,01. A adequação da amostra foi verificada pelo KMO (Kaiser-Meyer-Olkim) de 0,897. Na análise das comunalidades[iii], observou-se que as variáveis IOC14 [iv] , IOC17 e IOC18 apresentaram valores menores que 0,5, indicando a exclusão dessas variáveis da análise. Ao rodar a fatorial novamente, a variável IOC04 apresentou comunalidade de 0,499 
que demandou sua exclusão, da mesma forma que as variáveis excluídas anteriormente. Após essas exclusões, nenhuma variável apresentou comunalidade inferior a 0,5 .

A extração dos fatores foi realizada com base no autovalor, sendo considerado 1,0 o autovalor mínimo para a composição do fator. A solução fatorial encontrada com 17 variáveis, distribuídas em cinco fatores obteve um poder explicativo de $64,879 \%$ da variância dos itens. Os cinco fatores extraídos apresentaram autovalores iniciais de 6,060;1,641;1,229; 1,091 e 1,008. O Fator 5 foi composto por apenas uma variável (IOC02), não alcançando o mínimo de três variáveis para explicar o fator. Dessa forma, o Fator 5 e a Variável IOC02 foram desconsiderados da análise.

Os fatores da Escala de Identificação Organizacional Cooperativa (IOC) foram denominados com base na escala de Stoner, Perrewe e Hofacker (2011), que utilizou as dimensões de Apego Afetivo, Ajuste ao Grupo, Autocategorização e Comportamental; no estudo de Walumbwa et al. (2011) que utilizou as dimensões Cognitiva e Afetiva; e na escala de Thomaz e Brito (2010) que dimensionou a identificação organizacional como Cognitiva, Afetiva, Avaliativa e Comportamental.

Assim, o Fator 1 foi denominado de Ajuste ao Grupo e reuniu cinco itens explicando 20,437\% da variância observada. Apresenta itens relativos à inserção do colaborador no grupo de trabalho, bem como o reconhecimento do indivíduo como parte do grupo. Se refere a quanto o colaborador se ajusta ao grupo. Pode ser definido como reconhecimento do indivíduo como parte do grupo, à percepção do indivíduo como peça importante da engrenagem, perfeitamente ajustado às outras peças. $\mathrm{O}$ indivíduo, quando plenamente ajustado ao grupo, não necessita representar um papel, pois existe afinidade de valores e crenças, possibilitando a manifestação de seu verdadeiro "eu” (Stoner, Perrewe, \& Hofacker, 2011).

Em seguida, denominou-se o Fator 2 como Comportamental, agrupando quantro itens relativos à postura com relação ao trabalho e explicando $13,892 \%$ da variância observada. Esse agrupamento se refere ao comportamento dos colaboradores perante ao grupo. Pode ser definido como a postura manifestada pelos colaboradores diante às normas explícitas e implícitas do grupo, assim como nos ritos da organização e à adesão às regras e deliberações realizadas no grupo. Os relacionamentos tendem a ser mais de amizade do que de coleguismo (Christ et al., 2003; Stoner, Perrewe, \& Hofacker, 2011).

O terceiro fator foi denominado como a dimensão de Afetividade da escala, com quatro itens e 13,523\% da variância explicada. Aqui, reuniram-se os itens relacionados ao vínculo afetivo do colaborador com a cooperativa, bem como a disseminação de seus valores. Pode ser definido como o vínculo afetivo do indivíduo com o grupo, sentimento de pertença e preocupação com a perenidade desse vínculo. $O$ indivíduo deseja a perenidade do grupo e de seu vínculo, defendendo seu grupo perante adversidades (Christ et al., 2003; Edwards \& Peccei, 2007; Johnson, Morgeson, \& Hekman, 2012; Stoner, Perrewe, \& Hofacker, 2011).

Por fim, denominou-se o Fator 4 como a dimensão de Identificação Cognitiva, com três itens e 9,660\% da variância explicada. Nesse fator, agruparam-se os itens relacionados a percepção pelo indivíduo do que a organização espera dela, sempre procurando atender às expectativas do grupo e reduzir a incerteza social. $\mathrm{O}$ indivíduo se autodefine como membro da organização e se esforça por sua manutenção como membro do grupo (Thomaz \& Brito, 2010); Walumbwa et al., 2011); Johnson, Morgeson, \& Hekman, 2012).

A confiabilidade dos Fatores 1, 2 e 3 extraídos foi considerada satisfatória, de acordo com a interpretação de Hair et al. (2005), indicando uma associação muito boa para dimensão de Ajuste ao Grupo (0,864), boa associação para a dimensão de Afetividade (0,703), associação moderada para a dimensão Comportamental $(0,656)$ e baixa associação para a Identificação Cognitiva (0,551). A análise fatorial exploratória possibilitou a detecção de quatro construtos: de Ajuste ao Grupo, Comportamental, de Afetividade e de Identificação Cognitiva.

A análise fatorial confirmatória foi realizada individualmente pelos construtos de primeira ordem. $\mathrm{O}$ primeiro construto analisado foi o de "Ajuste ao Grupo", composto por cinco variáveis, todas com cargas superiores a 0,5. A melhoria dos índices de ajuste do modelo foi dada pela inserção de uma correlação entre o erro da variável IOC07 - "Percebo que as minhas opiniões sobre o trabalho são consideradas pela cooperativa" 
e o erro da variável IOC05 - "A minha participação nas decisões do meu setor é valorizada pela cooperativa". Essa correlação se justifica devido ao fato de as variáveis pertencerem ao mesmo construto de Ajuste ao Grupo e elaboradas com base no valor de Democracia. Finalizada a análise desse construto, seguiu-se para o próximo. A análise do construto "Comportamental" composto por quatro variáveis, todas com cargas superiores a 0,5 , apresentou o índice RMSEA > 0,07 (0,086), porém, o software Amos utilizado para a análise, não sugeriu nenhuma modificação. Como os índices de confiabilidade foram aceitáveis, optou-se por manter o construto. O construto de "Afetividade" com quatro variáveis, apresentou todas variáveis com cargas superiores a 0,5. Analisando as medidas de ajuste, constatou-se que o modelo não necessita de alterações. Assim, o construto permaneceu inalterado.

Ao analisar o construto de Identificação Cognitiva, com três variáveis, verificou-se que esse modelo estava exatamente identificado, ou seja, o mesmo número de graus de liberdade necessários para estimar todos os parâmetros livres. Byrne (2016) sugere a fixação de parâmetros para resolver esse problema, porém, constatou-se que os erros das variáveis do construto de Identificação Cognitiva são significativamente diferentes, não sendo possível a fixação de sua variância. Devido ao fato de a confiabilidade do construto ser baixa (alfa de Cronbach 0,5 > 0,6) e a impossibilidade de correção do modelo exatamente justificado, optouse por sua exclusão.

Após a validação dos construtos de $1^{a}$ ordem, passou-se para a avaliação do construto de $2^{\mathrm{a}}$ ordem: Identificação Organizacional Cooperativa. Foram necessárias inserir duas correlações para ajuste do modelo. O modelo foi recalculado após cada alteração, dessa forma, a ordem das inserções foi a seguinte: $1^{\text {a }}$ entre o erro da variável IOC07 - "Percebo que as minhas opiniões sobre o trabalho são consideradas pela cooperativa" e o erro da variável IOC05 - "A minha participação nas decisões do meu setor é valorizada pela cooperativa”; e, $2^{a}$ entre o erro da variável IOC08 - "Sinto que sou tratado (a) da mesma forma que meus colegas de trabalho" e o erro da variável IOC05 - "A minha participação nas decisões do meu setor é valorizada pela cooperativa".

A primeira correlação se justifica devido ao fato de as duas variáveis, IOC07 e IOC05, além das variáveis pertencerem ao mesmo construto, ambas possuem ligação com o valor de Democracia. Esse valor foca na livre manifestação das opiniões e na participação das decisões. Na segunda correlação, IOC08 e IOC05, embora tenham ligação aos valores de Democracia e Igualdade e Equidade, focam na oportunidade de participação de forma igualitária. O construto de Ajuste ao Grupo, a partir do qual ocorreu todas as correlações, avalia o reconhecimento do indivíduo como membro do grupo e sua autopercepção como parte importante do grupo (Stoner, Perrewe, \& Hofacker, 2011).

Os critérios de validade convergente foram atendidos por meio da variância extraída, confiabilidade composta e alfa de Cronbach, e o modelo de mensuração da escala de Identificação Organizacional Cooperativa atende aos índices mais usados na avaliação da qualidade de ajuste. Ressalta-se que foram realizados apenas os ajustes fundamentados teoricamente e que atendiam minimamente às medidas estatísticas indicadas. Segundo Hair et al. (2009), deve-se optar por poucas modificações a fim de preservar a integridade teórica do modelo de mensuração.

\subsection{Avaliando o Clima Organizacional segundo a percepção dos Entrevistados}

A Análise Fatorial Exploratória (AFE) da escala de Clima Organizacional (CO) iniciou pela análise preliminar da matriz R ou matriz de correlação, a qual indicou que as variáveis " 31 ", "32" e " 36 " não se correlacionam com as demais variáveis, pois apresentaram significâncias superiores a 0,05. Assim, optouse pela exclusão dessas variáveis e rodou-se novamente a fatorial sem as variáveis excluídas. A nova matriz apresentou variáveis correlacionadas entre si, sem problemas de singularidade. A determinante apresentou um valor de 0,003 , portanto, maior que o mínimo (0,00001) indicando que não haverá problemas de multicolinearidade. 
A adequação da amostra foi verificada pelo KMO (Kaiser-Meyer-Olkim) de 0,908. Kaiser (1974 citado por Field, 2009) recomenda um KMO mínimo de 0,5 , sendo os valores acima de 0,9 considerados excelentes. Portanto, a análise de fatores é apropriada para esses dados. O teste de esferecidade de Bartlett apresentou alta significancia com p < 0,001, indicando que a análise de fatores é apropriada (Field, 2009) .

A solução fatorial encontrada apresentou três fatores teoricamente suportados, explicando $67 \%$ da variância dos itens. As comunalidades das variáveis foram acima de 0,5 , demonstrando que as 12 variáveis são adequadamente explicadas pela solução fatorial (Hair et al., 2009). Os fatores extraídos possuem autovalores de 3,801, 2,241 e 2,005. A matriz de componente rotativa revela os fatores emergidos, bem como as varáveis que compõe esses valores (todas com carga superior a 0,5 ).

O primeiro fator reuniu seis itens e explicou 31,68\% da variância observada. Apresenta itens relativos às relações verticais do trabalho em ambas direções. Além disso, apresenta itens que avaliam a abertura à inovação e resolução de problemas por iniciativa dos colaboradores. Esse fator foi denominado como aspecto Afetivo do Clima Organizacional e obteve bom coeficiente de precisão $(0,881)$. Ostroff (1993) chamou de Afetiva a dimensão do clima organizacional oriunda do envolvimento pessoal dos colaboradores, das relações interpessoais ou sociais. Carr et al. (2003) relataram que a dimensão Afetiva ocorre quando, no clima organizacional, é enfatizado o interpessoal, as relações sociais entre os trabalhadores, incluindo aspectos de participação, cooperação, cordialidade e recompensas.

O segundo fator agrupou três itens relativos à definição do trabalho, explicando $18,68 \%$ da variância observada. Esse agrupamento se refere aos objetivos, prazos e escopo do trabalho. Também avalia o cumprimento de prazos na execução do trabalho. Esse fator obteve um coeficiente de precisão satisfatório $(0,783)$ e denominado como aspecto Instrumental do Clima Organizacional. A denominação Instrumental foi utilizada por Ostroff (1993) e Carr et al. (2003). Ostroff (1993) relaciona a dimensão instrumental quando o envolvimento do colaborador é na tarefa e nos processos de trabalho. Carr et al. (2003) complementam, referindo-se à dimensão instrumental como aquela que enfatiza o envolvimento dos indivíduos nas das tarefas realizadas na organização, incluindo aspectos relacionado à realização, hierarquia, estrutura e recompensas extrínsecas.

Por fim, o terceiro fator também obteve coeficiente de precisão satisfatório $(0,720)$ e contempla três itens com $16,71 \%$ da variância explicada. Aqui, reuniram-se os itens relacionados à ligação do colaborador com o trabalho, incluindo as oportunidades de crescimento, prestígio e suporte organizacional. Esse fator foi denominado como aspecto Cognitivo do Clima Organizacional.

A Análise Fatorial Exploratória (AFE) da escala de Clima Organizacional (CO), que inicialmente continha 15 variáveis, identificou três fatores - Afetivo, Instrumental e Cognitivo -, distribuídos em 12 variáveis. A validação, como na escala de Identificação Organizacional Cooperativa, foi realizada individualmente nos construtos de primeira ordem, seguindo para a validação do construto de segunda ordem. O construto Afetivo do Clima Organizacional com seis variáveis, todas com cargas superiores a 0,7, necessitou da inserção de duas correlações a fim de atender às medidas de ajuste do modelo. As inserções foram realizadas nos erros das variáveis com maior índice de modificação indicado pelo software Amos 21, nessa ordem: $1^{\text {a }}$ entre o erro da variável CO27[v] - "Minhas sugestões sobre o trabalho são ouvidas" e o erro da variável CO26 - "As contribuições para inovar são apreciadas no meu trabalho"; e, 2a entre o erro da variável CO25 - "Meus superiores me encorajam quando tenho problemas, para que eu possa resolvê-los" e o erro da variável CO26 - “As contribuições para inovar são apreciadas no meu trabalho".

A cada inserção de correlação houve nova análise dos índices do modelo. As inserções dessas duas correlações se justificam por pertencerem ao mesmo construto.

A seguir, passou-se para a análise dos construtos Instrumental e Cognitivo. Ambos construtos estavam exatamente identificados, ou seja, possuíam três variáveis que resultam no número de graus de liberdade necessários para estimar todos os parâmetros livres. Hair et al. (2009) relatam que modelos exatamente identificados não testam uma teoria. 
Uma abordagem utilizada para resolver o problema de modelos exatamente identificados é a fixação de parâmetros (Byrne, 2016). O software Amos 21 fornece um mecanismo para selecionar prováveis candidatos para fixação de parâmetros, o Método da Diferença Crítica (MDC). Assim, constatou-se que os erros das variáveis CO34 e CO33, do construto Instrumental, não são significativamente diferentes, possibilitando a fixação da sua variância.

Da mesma forma, no construto Cognitivo também foram fixadas a variância das variáveis $\mathrm{CO} 22$ e CO23. Como os erros dessas variáveis não são significativamente diferentes, a fixação de parâmetros também permitiu resolver o problema de identificação do construto Cognitivo. Com a fixação de parâmetros nos referidos erros das variáveis dos construtos Instrumental e Cognitivo, foi possível calcular o Qui-Quadrado, bem como sua significância.

Após a validação dos construtos de $1^{a}$ ordem (Afetivo, Instrumental e Cognitivo), passou-se para a validação do construto de $2^{a}$ ordem: Clima Organizacional. De acordo com a análise dos índices de ajuste, foi necessária a inserção de uma correlação entre os erros das variáveis CO34 - "Meu trabalho está adequadamente definido" e CO33 - “Os objetivos do meu trabalho estão claramente definidos”. A inserção da correlação entre os erros das variáveis CO34 e CO33 se justifica por pertencerem ao mesmo construto (Instrumental), possuindo interação. Os critérios de validade convergente foram atendidos por meio da variância extraída, confiabilidade composta e alfa de Cronbach.

Verificou-se que o modelo final satisfaz aos índices de ajustes mais utilizados. Salienta-se que foram realizados apenas as alterações necessárias ao atendimento dos índices de ajuste, a fim de preservar a integridade teórica do construto.

\subsection{Análise dos caminhos estruturais: Influência da Identificação Organizacional Cooperativa sobre o Clima Organizacional}

A fim de alcançar o objetivo do estudo, realizou a análise dos caminhos estruturais do construto Identificação Organizacional Cooperativa (IOC) sobre o construto de Clima Organizacional. A IOC é formada por três dimensões: Ajuste ao Grupo, Comportamental e de Afetividade. As dimensões da IOC de Ajuste ao Grupo e Afetividade influenciam o CO Afetivo ao nível de 1\%, porém, a influência da dimensão Comportamental não apresentou significância máxima de 5\%, sendo necessária a exclusão do construto Comportamental. Assim, passou-se para a análise do modelo estrutural que não produziu resultados dentro do nível adequado $\left(\mathrm{X}^{2}\right.$ $=293,873 ; \mathrm{GL}=84 ; \mathrm{X}^{2} / \mathrm{GL}=3,498 ; \mathrm{GFI}=0,908 ; \mathrm{CFI}=0,919 ;$ e RMSEA =0,085), necessitando da realização de ajustes.

O Amos sugeriu a inserção de correlações entre os erros dos construtos de Ajuste ao Grupo e Afetividade, porém, por tratar-se de indicadores distintos, optou-se por inserir relações de influência. A direção da relação (Afetividade <- Ajuste ao Grupo) foi embasada teoricamente. Os resultados indicam que o aspecto Afetivo do Clima Organizacional é influenciado diretamente pelas dimensões de Ajuste ao Grupo $(\mathrm{p}<0,001)$ e Afetividade $(\mathrm{p}<0,005)$. A dimensão de Ajuste ao Grupo ainda influencia indiretamente o aspecto Afetivo $(\mathrm{p}<0,001)$ por meio da dimensão de Afetividade. De fato, a forma como o indivíduo se ajusta ao grupo influencia a afetividade de pertencer ao grupo e, por consequência, influencia o clima afetivo. Após a realização das modificações mencionadas anteriormente, os índices de ajuste do modelo melhoraram consideravelmente, alcançando os níveis recomendados por Hair et al. (2009). A Tabela 2 apresenta os índices de ajuste do modelo. 
Tabela 2: Índices de ajuste do modelo estrutural do Aspecto Afetivo do Clima Organizacional

\begin{tabular}{lll}
\hline Índices de Ajuste & $\begin{array}{l}\text { Modelo } \\
\text { inicial }\end{array}$ & $\begin{array}{l}\text { Modelo } \\
\text { final }\end{array}$ \\
\hline Qui-quadrado (c²) & 536,719 & 185,250 \\
Qui-quadrado (Significância) & 0,000 & 0,000 \\
Graus de Liberdade (GL) & 145 & 83 \\
C $^{2} / \mathrm{GL}$ & 3,702 & 2,232 \\
GFI - Goodness-of-fit & 0,863 & 0,935 \\
CFI - Comparative Fit Index & 0,870 & 0,961 \\
RMSEA - Roat Mean Square Error of & 0,089 & 0,060 \\
Aproximation & & \\
\hline
\end{tabular}

Fonte: Dados da pesquisa.

O próximo caminho a ser analisado são as relações do construto Instrumental do Clima Organizacional. As relações com os construtos Ajuste ao Grupo e de Afetividade apresentaram significância ao nível de 5\%, ao contrário da dimensão Comportamental que não alcançou significância e, portanto, foi excluída. Após essa exclusão, as correlações entre os erros das variáveis CO33 (e33) e CO34 (e34) e IOC08 (e08) e IOC05 (e05), não obtiveram significância ao nível de $5 \%$ e, também, precisaram ser excluídas. Após essas exclusões o modelo não alcançou os índices de ajustamento, sendo indicado pelo Amos uma correlação entre os erros dos construtos de Ajuste ao Grupo e Afetividade. Por se tratar de indicadores distintos, optou-se por inserir uma relação de influência embasada teoricamente (Afetividade <- Ajuste ao Grupo), o que gerou insignificância na influência da Afetividade sobre o aspecto Instrumental do Clima.

Assim, como não foi possível ajustar o modelo, optou-se pela exclusão da dimensão de Afetividade na análise de caminhos. Esse resultado indica que apenas a dimensão de Ajuste ao Grupo influencia no aspecto Instrumental do Clima Organizacional. Dessa forma, pode-se presumir que os aspectos relacionados à atribuição de tarefas e recompensas na organização correspondem ao status quo do indivíduo no grupo. Os índices do modelo apresentaram adequabilidade, não necessitando de modificações adicionais.

Por fim, foi analisado o caminho do construto Cognitivo do Clima Organizacional. O caminho estrutural Cognitivo <- Comportamental não apresentou significância ao nível de 5\%, sendo necessária a exclusão do construto Comportamental. Com essa exclusão a correlação entre as variáveis IOC08 (e08) e IOC05 (e05) não foi mais significativa e, portanto, retirada do modelo. Apesar da retirada do construto, o modelo não alcançou os índices de mínimos necessários para sua adequabilidade $\left(X^{2}=248,078 ; G L=52 ; X^{2} / G L=4,771\right.$; $\mathrm{GFI}=0,902$; $\mathrm{CFI}=0,884$; e RMSEA $=0,105$ ).

Com o intuito de melhorar os índices de ajustamento do modelo foram inseridas correlações entre os erros da variável IOC19 (e19) e do construto Cognitivo (eCOG) que, embora sejam de construtos diferentes, estão relacionados teoricamente. Além desses ajustes, o Amos sugeriu inserir uma correlação entre os erros dos construtos de Ajuste ao Grupo e Afetividade. Porém, como ocorreu na análise do primeiro caminho, optou-se por inserir uma relação de influência devido ao fato de serem indicadores distintos.

A análise do caminho indicou que o aspecto Cognitivo do Clima Organizacional é influenciado direta e indiretamente pela dimensão de Ajuste ao Grupo da Identificação Organizacional Cooperativa. Indiretamente, o construto de Ajuste ao Grupo utiliza a Afetividade como mediadora da influência sobre o aspecto Cognitivo do Clima Organizacional. A partir desse resultado, é possível inferir que a afetividade pode influenciar o envolvimento psicológico e recompensa intrínseca do aspecto Cognitivo do Clima Organizacional. Assim como o Ajuste ao Grupo pode influenciar as características de autonomia, crescimento e autodesenvolvimento do aspecto Cognitivo do Clima Organizacional. Supóe-se, ainda, que o Ajuste ao Grupo influencie a Afetividade por meio do sentimento de pertença e engajamento com o cooperativismo. A verificação dos índices de ajustamento indicou que o modelo alcançou os índices mínimos de adequabilidade. 
A Figura 2 apresenta a síntese das relações que se mostraram significativas na análise de caminhos entre as dimensões da Identidade Organizacional Cooperativa (IOC) e os aspectos do Clima Organizacional (CO). Pode-se observar que ao analisar os caminhos em conjunto, a influência da Afetividade (IOC) sobre o Afetivo (CO) que já possuía uma carga pequena $(0,220)$, não alcançou o nível mínimo de significância $(\mathrm{p}<0,005)$. Dessa forma, o caminho Afetivo <- Afetividade foi excluído.

Desse modo, observa-se que a dimensão da IOC que possui mais influência sobre o $\mathrm{CO}$ é a dimensão de Ajuste ao Grupo, interferindo nos três aspectos do Clima Organizacional (CO). A dimensão comportamental da IOC não apresentou influência significativa sobre os aspectos do $\mathrm{CO}$, sendo excluída da análise conjunta. A dimensão de Afetividade da Identificação Organizacional Cooperativa (IOC) intermedia a influência indireta da dimensão de Ajuste ao Grupo sobre o aspecto Cognitivo do CO.

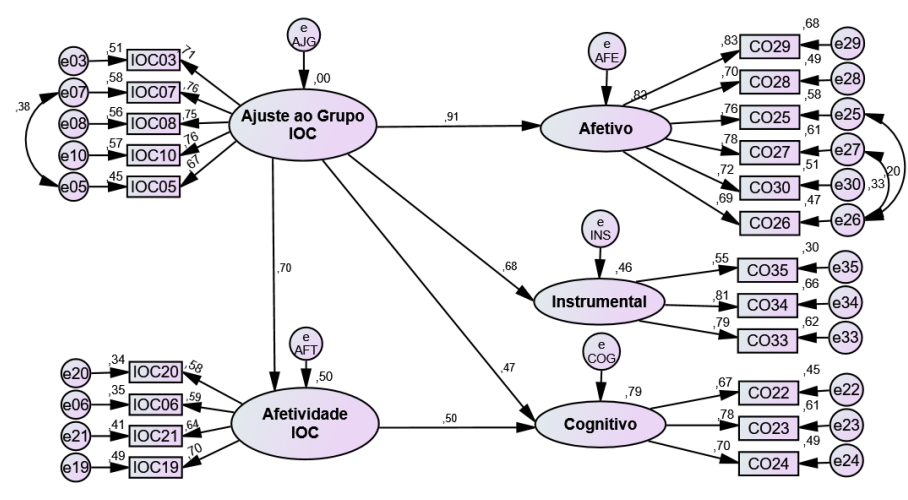

Figura 2:Análise conjunta de caminhos das dimensões da IOC $\mathrm{x}$ aspectos do CO Fonte: Dados da pesquisa.

Nota: Todos os coeficientes apresentados foram significativos ao nível de $1 \%$.

A validação do modelo integrado de influência da Identificação Organizacional Cooperativa (IOC) sobre o Clima Organizacional (CO) se deu por meio da análise dos índices de ajustes recomendado por Hair et al. (2009). O modelo inicial apresentou a variância do erro do construto de Clima Organizacional negativa $(\mathrm{eCO}=-0,007)$. $\mathrm{O}$ software Amos sugeriu a inserção de uma correção entre os construtos de Afetividade (ICO) e Cognitivo (CO). Após essa inserção foi possível rodar o modelo inicial, porém, não alcançou os índices suficientes para a validação do modelo $\left(\mathrm{X}^{2}=601,879 ; \mathrm{GL}=265 ; \mathrm{X}^{2} / \mathrm{GL}=2,271\right.$; $\mathrm{GFI}=0,875$; CFI $=0,918 ;$ RMSEA $=0,061)$, portanto, foram necessários ajustes ao modelo inicial.

Os ajustes ao modelo inicial seguiram a análise de caminhos, verificando que o construto Comportamental não influencia nenhum aspecto do Clima Organizacional, necessitando ser retirado do modelo. Ao retirar a dimensão Comportamental, não foi possível manter o construto de Identificação Organizacional Cooperativa com apenas dois construtos de identificação, pois o modelo ficaria subidentificado, ou seja, com mais parâmetros a serem estimados do que variâncias ou covariâncias de itens (HAIR et al., 2009). Assim, optou pela exclusão do construto de segunda ordem Identificação Organizacional Cooperativa (IOC), realizando a influência direta dos construtos de Ajuste ao Grupo e Afetividade sobre o construto de Clima Organizacional.

Ao excluir o construto de IOC, fez-se a ligação dos construtos de Ajuste ao Grupo e Afetividade por meio de uma seta de influência, seguindo o sugerido pela análise de caminhos. Após essas exclusões o modelo obteve uma significativa melhora $\left(\mathrm{X}^{2}=419,347 ; \mathrm{GL}=181 ; \mathrm{X}^{2} / \mathrm{GL}=2,317\right.$; GFI $=0,896$; $\mathrm{CFI}=0,935$; RMSEA 
$=0,062)$, porém, essa melhora ainda não foi considerada adequada aos índices de ajustamento do modelo. Portanto, verificou-se os índices de modificação sugerido pelo Amos e realizou-se as seguintes alterações: exclusão das correlações entre os erros das variáveis IOC05 (e05) e IOC08 (e08) e entre os erros das variáveis $\mathrm{CO} 26$ (e26) e CO25 (e25). Ainda foram incluídas, conforme sugestão do Amos, correlações entre os erros das variáveis CO28 (e28) e CO29 (e29); entre os erros das variáveis CO25 (e25) e CO27 (e27); entre os erros das variáveis $\mathrm{CO} 25$ (e25) e CO22 (e22); e entre os erros das variáveis $\mathrm{CO} 27$ (e27) e CO23 (e23). Justificam-se essas alterações devido ao fato de pertencerem ao mesmo construto do Clima Organizacional e, portanto, estão teoricamente relacionadas.

Hair et al. (2009) sugerem, ainda, que o efeito moderador seja testado com um modelo alternativo. Dessa forma, realizou-se outro modelo desconsiderando construto de $1^{\text {a }}$ ordem de Afetividade. Os índices de ajustamento apresentaram melhora com apenas a exclusão das correlações entre os erros das variáveis IOC05 (e05) e IOC08 (e08), evidenciando que o modelo com moderação não é sustentado. O modelo integrado final validado pode ser observado na Figura 3. Os Índices de Ajustes dos Modelos Inicial e Final (com e sem moderação) podem ser visualizados na Tabela3. Os índices mínimos sugeridos por Hair et al. (2009) foram alcançados: $\mathrm{X}^{2} / \mathrm{GL}<3$; GFI > 0,90; CFI > 0,92; e, RMSEA < 0,07. Analisadas a qualidade de ajuste do modelo, o próximo passo foi o exame das estimativas paramétricas individuais. As relações entre os construtos apresentaram coeficientes padronizados acima de 0,7 e foram a significativas a $1 \%$ e, na direção prevista.

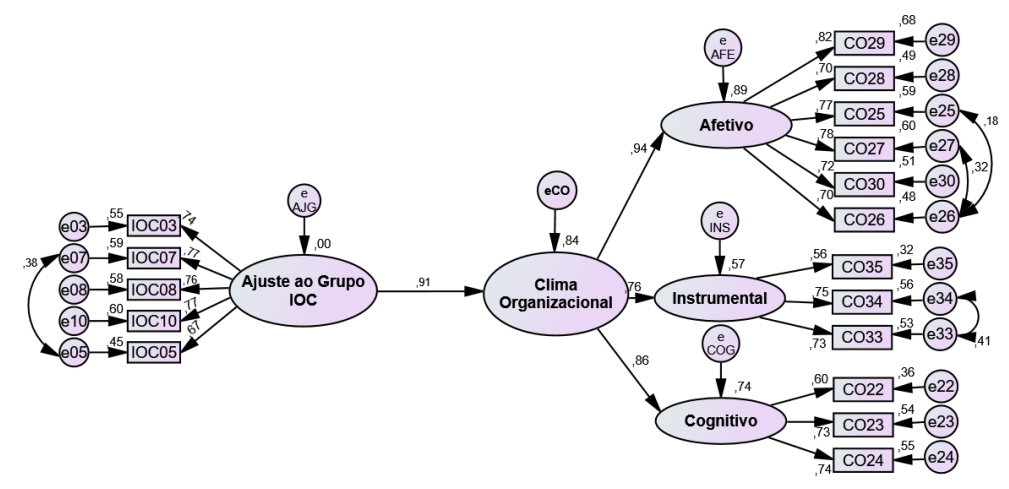

Figura 3:Modelo Integrado Final de Influência da dimensão de Ajuste ao Grupo da Identificação Organizacional Cooperativa sobre o Clima Organizacional Fonte: Dados da pesquisa. 
Tabela 3: Índices de ajuste do modelo integrado de Influência da dimensão de Ajuste ao Grupo e Afetividade da Identificação Organizacional Cooperativa sobre o Clima Organizacional

\begin{tabular}{llll}
\hline & $\begin{array}{l}\text { Modelo } \\
\text { inicial }\end{array}$ & Modelo final & \\
\cline { 2 - 4 } $\begin{array}{l}\text { Índices de } \\
\text { Ajuste }\end{array}$ & IOC à Co & $\begin{array}{l}\text { Com variável } \\
\text { moderadora } \\
\text { AJUG-AFET/IOC } \\
\text { à CO }\end{array}$ & $\begin{array}{l}\text { Sem } \\
\text { variável } \\
\text { moderadora } \\
\text { AJUG/IOC à } \\
\text { CO }\end{array}$ \\
\hline $\begin{array}{l}\text { Qui-quadrado } \\
\text { (C²) }\end{array}$ & 601,879 & 393,915 & 266,111 \\
$\begin{array}{l}\text { Qui-quadrado } \\
\text { (SignificânCia) }\end{array}$ & 0,000 & 0,000 & 0,000 \\
$\begin{array}{l}\text { Graus de } \\
\text { Liberdade (GL) } \\
\text { CGL }\end{array}$ & 265 & 179 & 114 \\
$\begin{array}{l}\text { GFI } \\
\text { CFI }\end{array}$ & 2,271 & 2,201 & 2,334 \\
RMSEA & 0,875 & 0,900 & 0,916 \\
\hline
\end{tabular}

Fonte: Dados da pesquisa.

O modelo final foi composto por um construto de segunda ordem, quatro construtos de primeira ordem e 17 variáveis. O construto de segunda ordem, Identificação Organizacional Cooperativa (IOC), ficou composto apenas pelo construto de primeira ordem de Ajuste ao Grupo, sendo necessária sua exclusão. Embora o construto de segunda ordem IOC tenha sido validado com três construtos de primeira ordem, quando a relação com o Clima Organizacional (CO) foi efetuada, evidenciou-se que apenas a dimensão de Ajuste ao Grupo da IOC influenciava o CO e que a dimensão de Afetividade influenciava apenas o aspecto Cognitivo do $\mathrm{CO}$ e como mediadora. Como a moderação acabou não se confirmando, assumiu-se que apenas a dimensão de Ajuste ao Grupo influencia o Clima Organizacional.

Hair et al. (2009) recomendam o exame das estimativas de variância explicada para os construtos endógenos $\left(\mathrm{R}^{2}\right)$. Em Modelagem de Equações Estruturais essa estatística é dada pela Correlação Múltipla Quadrática, apresentada na Tabela 4.

Tabela 4: Coeficientes de explicação dos construtos

\begin{tabular}{l|c}
\hline \multicolumn{1}{c|c}{ Construtos } & $\mathbf{R}^{\mathbf{2}}$ \\
\hline Ajuste ao Grupo da IOC & 0,000 \\
\hline Clima Organizacional & 0,837 \\
\hline Afetivo do CO & 0,892 \\
\hline Cognitivo do CO & 0,742 \\
\hline Instrumental do CO & 0,571 \\
\hline
\end{tabular}

Fonte: Dados da pesquisa.

Os resultados evidenciam que os aspectos Afetivo, Cognitivo e Instrumental explicam 83,7\% do Clima Organizacional. Da mesma forma, o aspecto Afetivo do CO é $89,2 \%$ explicado por suas variáveis, o Cognitivo é $74,2 \%$ explicado, e o Instrumental tem $57,1 \%$ de sua variância explicada por suas variáveis.

\section{Considerações Finais}

Após a formação e compreensão da Identidade Organizacional Cooperativa (IdCoop), foi possível construir e validar uma escala de Identificação Organizacional Cooperativa (IOC). A escala inicialmente elaborada 
e revisada por especialistas com 21 questões, foi validada por meio das análises fatoriais exploratória e confirmatória, com 13 variáveis representativas de três dimensões da Identificação Organizacional Cooperativa, quais sejam, Ajuste ao Grupo, Comportamental e Afetividade. O modelo de mensuração da escala de IOC atendeu à índices de avaliação de medidas de ajuste absoluto, incluindo índices de qualidade de ajuste, de má qualidade de ajuste, além de medida de ajuste incremental.

A validação da escala reduzida de clima organizacional para cooperativas de crédito, iniciou-se pela análise fatorial exploratória que resultou em uma escala com 12 variáveis distribuídas em três fatores: Afetivo, Instrumental e Cognitivo. A continuação da validação da escala se deu por meio da análise fatorial confirmatória que ratificou os 12 construtos de primeira ordem. O modelo final da Escala Reduzida de Clima Organizacional (ERCO) satisfez à índices de avaliação de medidas de ajuste absoluto, incluindo índices de qualidade de ajuste e má qualidade de ajuste, além de medida de ajuste incremental.

$\mathrm{Na}$ análise de caminhos, o primeiro aspecto do $\mathrm{CO}$ analisado foi o Afetivo, que foi influenciado direta e significativamente apenas pela dimensão de Ajuste ao Grupo da IOC. Nessa análise, observou-se também uma influência indireta da dimensão de Ajuste ao Grupo da IOC sobre o aspecto Afetivo do CO intermediado pela dimensão de Afetividade da IOC. A influência indireta da dimensão de Ajuste ao Grupo sobre o aspecto Afetivo (CO), mediada pela dimensão de Afetividade (IOC), justifica-se ao considerar que a forma como o indivíduo se ajusta ao grupo influencia a afetividade de pertencer ao grupo e, por consequência, influencia o clima afetivo.

$\mathrm{O}$ aspecto Instrumental do $\mathrm{CO}$ também foi influenciado direta e significantemente apenas pela dimensão de Ajuste ao Grupo da IOC, sem receber nenhuma outra influência indireta. Em relação ao aspecto Cognitivo do CO, evidenciou-se que ele é influenciado diretamente pelas dimensões de Ajuste ao Grupo e de Afetividade da IOC. Além disso, observou-se uma influência indireta da dimensão de Ajuste ao Grupo sobre o aspecto Cognitivo do $\mathrm{CO}$, mediada pela dimensão de Afetividade da IOC. Essa mediação da dimensão de Afetividade (IOC) pode ter ocorrido em virtude de sua influência no envolvimento psicológico e nas recompensas intrínsecas do aspecto Cognitivo (CO), a partir do qual a dimensão de Afetividade (IOC) estaria recebendo influência da dimensão de Ajuste ao Grupo (IOC) por meio dos sentimentos de pertença e engajamento com o cooperativismo.

Assim, a dimensão que mais influenciou o Clima Organizacional foi a de Ajuste ao Grupo (IOC), agindo nos três aspectos do Clima Organizacional - Afetivo, Instrumental e Cognitivo. Na validação do modelo integrado, o modelo inicial recebeu os ajustes de acordo com a análise de caminhos estruturais e com os índices de modificação sugerido pelo Amos. Todas as alterações foram fundamentadas teoricamente.

O exame das estimativas paramétricas individuais, demonstrou que as relações entre os construtos apresentaram coeficientes padronizados acima de 0,7 com significância a $1 \%$ e na direção prevista. O modelo final combinou um construto de segunda ordem, quatro construtos de primeira ordem e 17 variáveis. Devido ao fato de o construto de segunda ordem Identificação Organizacional Cooperativa (IOC) ter sido formado apenas pelo construto de primeira ordem de Ajuste ao Grupo, o construto IOC foi excluído do modelo final. Os resultados finais do modelo demonstraram que o Clima Organizacional é 83,7\% explicado pelos aspectos Afetivo, Cognitivo e Instrumental, ou seja, os aspectos Afetivo, Cognitivo e Instrumental representam 83,7\% do construto Clima Organizacional, o que é considerado um percentual muito bom.

Entre as limitações do estudo, pode-se a citar escolha das variáveis e construtos, que mesmo estando ancoradas teórica e metodologicamente, podem ser percorridas por outros caminhos. A inclusão de novos construtos e variáveis podem enriquecer o estudo.

Como sugestões para futuras pesquisas, ressalta-se sua replicação internacional, ou nacional em diferentes regiões brasileiras, com cooperativas de crédito, a fim de analisar as interferências culturais. Ainda, pode ser estendido para outros ramos do cooperativismo. 


\section{REFERÊNCIAS}

Alvesson, M., \& Willmott, H. (2002, July). Identity Regulation as Organizational Control: Producing the Appropriate Individual. Journal of Management Studies, 39(5), 619-644.

Ashforth, B., \& Mael, F. (1989, Jan). Social Identity Theory and the Organization. The Academy of Management Review, 14(1), 20-39.

Banco Central do Brasil. (2016). Sistema Financeiro Nacional. Retrieved Setembro 17, 2017, from Panorama do Sistema Nacional de Crédito Cooperativo: http://www.bcb.gov.br/pre/microFinancas/coopcar/pdf/panoram a_de_cooperativas.pdf

Bandeira, E., \& Santos, V. T. (2006). Desenvolvimento local: sustentabilidade ou subordinação? Retrieved 10 2016, 28, from Departamento de Geografia da Universidade Estadual de Maringá: http://www.dge.uem.br/semana/eixo 3/trabalho_35.pdf

Baptista, M., Rueda, F., Bartholomeu, D., Pires, S., \& Rochael, F. (2010, maio-ago). Suporte laboral e identificação organizacional: um estudo de validade. Aletheia, 32, 53-69.

Barbosa, T., Vicentin, M., \& Gavião, M. (2011). Qualidade de vida e saúde bucal em crianças - Parte I: Versão brasileira do Child Perceptions Questionnaire 8-10. Ciência \& Saúde Coletiva, 16(10), 4077-4085.

Bardin, L. (2016). Análise de Conteúdo (1ª - $3^{a}$ reimp. ed.). São Paulo: Edições 70.

Bhattacharya, C., \& Sen, S. (2003, April). Consumer-Company Identification: a framework for understanding consumers' relationships with companies. Journal of Marketing, 67, 76-88.

Bialoskorski Neto, S. (2012). Economics and management of cooperative organizations. São Paulo: Atlas.

Bispo, C. A. (2006, Maio/Ago). Um novo modelo de pesquisa de clima organizacional. Produção, 16(2), p. 258-273.

Borges, E. B., \& Zimath, S. C. (2011, Jun). Conhecendo o Clima Organizacional de uma Cooperativa de Crédito de Joinvile. Anuário da Produção de Iniciação Cientifica Discente, 13(17), 265-277.

Brasil. (1971). Lei no 5.764, de 16 de dezembro de 1971. Retrieved Setembro 17, 2017, from Define a Política Nacional de Cooperativismo, institui o regime jurídico das sociedades cooperativas, e dá outras providências: http://ww w.planalto.gov.br/ccivil_03/leis/L5764.htm

Brasil. (2000). Lei no 10.097, de 19 de dezembro de 2000. Retrieved Maio 10, 2019, from Altera dispositivos da Consolidação das Leis do Trabalho - CLT, aprovada pelo Decreto-Lei no 5.452, de 1o de maio de 1943.: http s://www.planalto.gov.br/ccivil_03/Leis/L10097.htm

Byrne, B. (2016). tructural equation modeling with Amos: basic concepts, applications, and programming (3 ed.). New York: Routledge.

CAPES/MEC. (2018). Portal de Periódicos da Capes. Retrieved 05 15, 2018, from Buscar Assunto: http://www-periodicos-capes-gov-br.ez47.periodicos.capes.gov.br/index.php?option=com_pmetabu $s c a \& m n=88 \& s m n=88 \&$ type $=m \&$ metalib $=$ index. php?option $=$ com_pmetabusca\&mn $=88 \& s m n=88 \&$ type $=$ m\&metalib=aHR0cDovL3JucC1wcmltby5ob3N0ZWQuZXhsaWJyaXNncm91cC5jb20vcHJpbW9fbGlic $\mathrm{mF}$

Carmeli, A., Brammer, S., Gomes, E., \& Tarba, S. (2017). An organizational ethic of care and employee involvement in sustainability - related behaviors: a social identity perspective. Journal of Organizational Behavior, 38, 1380-1395.

Carr, J., Schmidt, A., Ford, J., \& DeShon, R. (2003). Climate Perceptions Matter: a meta-analytic path analysis relating molar climate, cognitive and affective states, and individual level work outcomes. Journal of Applied Psychology, $88(4), 605-619$.

Christ, O., van Dick, R., Wagner, U., \& Stellmacher, J. (2003). When teachers go the extra mile: Foci of organisational identification as determinants of different forms of organisational citizenship behaviour among schoolteachers. British Journal of Educational Psychology, 73, 329-341.

Dutton, J. E., Dukerich, J. M., \& Harquail, C. V. (1994, Junho). Organizational Images and Member Identification. Administrative Science Quarterly, 39(2), 239-263. 
Marcia Helena dos Santos Bento, et al. IdentificaÇão Organizacional Cooperativa: a influência de U...

Edwards, M., \& Peccei, R. (2007, Mar.). Organizational Identification: Development and testing of a conceptually grounded measure. European Journal of Work and Organizational Psychology, 16(1), 25-67.

Ferreira, M., \& Assmar, E. (2008). Cultura organizacional. In M. Siqueira, Medidas do Comportamento Organizacional: Ferramentas de Diagnóstico e de Gestão. (pp. 125-138). Porto Alegre: Artmed.

Field, A. (2009). Descobrindo a estatística usando o SPSS (2a ed.). Porto Alegre: Artmed.

Figueiredo, N. (2009). Cooperativas Sociais: alternativa para inserção. Porto Alegre: Evangraf.

Fleury, M. (1989, jan./mar.). Cultura Organizacional - os modismos, as pesquisas, as intervenções: uma discussão metodológica. Revista de Administração, 24(1), 3-9.

Fundação Sicredi. (2014). A Trajetória do Sicredi: uma história de cooperação. Porto Alegre: Fundação Socredi.

Fundação Sicredi. (2018). Relatório de Sustentabilidade. Sicredi, Porto Alegre.

Glick, W. (1985, Jul.). Conceptualizing and Measuring Organizational and Psychological Climate: Pitfalls in Multilevel. The Academy of Management Review, 10(3), 601-616.

Glisson, C., \& Green, P. (2011). Organizational climate, services, and outcomes in child welfare systems. Child Abuse \& Neglect, 35, 582-591.

Glisson, C., Landsverk, J., Schoenwald, S., Kelleher, K., Hoagwood, K., Mayberg, S., \& Green, P. (2008). Assessing the Organizational Social Context (OSC) of Mental Health Services: Implications for Research and Practice. Administration and Policy in Mental Health, 35, 98-113.

Hair, J. Jr., Babin, B., Money, A., \& Samuell, P. (2005). Fundamentos de Métodos de Pesquisa em Administração. Porto Alegre: Bookman.

Hair Jr., J., Black, W., Babin, B., Anderson, R., \& Tatham, R. (2009). Análise Multivariada de Dados (6 ed.). Porto Alegre: Bookman.

Hakak, L. (2015). Strategies for the resolution of identity ambiguity following situations of subtractive change. The Journal of Applied Behavioral Science, 51 (I), 129-144.

Hannah, S., Jennings, P., Bluhm, D., Peng, A., \& Schaubroeck, J. (2014). Duty orientation: theoretical development and preliminary construct testing. Organizational Behavior and Human Decision Processes, 123, 220-238.

Hatch, M., \& Schultz, M. (1997). Relations between organizational culture, identity and image. European Journal of Marketing, 31(5/6), 356-365.

Hentschel, T., Shemla, M., Wegge, J., \& Kearney, E. (2013). Perceived diversity and team functioning: the role of diversity beliefs and affect. Small Group Research, 44 (I), 33-61.

Hernandez, M., \& Guarana, C. (2018). An examination of the temporal intricacies of job engagement. Journal of Management, 44(5), 1711-1735.

Hofstede, G. (1998). Attitudes, Values and Organizational Culture: Disentangling the Concepts. Organization Studies, 19(3), 477-492.

Hogg, M., \& Terry, D. (2000, Jan). Social Identity and Self-Categorization Processes in Organizational Contexts. The Academy of Management Review, 25(01), 121-140.

Holyoake, G. (2014). Os 28 tecelóes de Rochdale (14. ed.). Porto Alegre: Sulina.

IBGE. (2019). Cidades e Estados. RS. Retrieved Janeiro 21, 2019, from Instituto Brasileiro de Geografia e Estatística: https://www.ibge.gov.br/cidades-e-estados/rs.html?

ILO. (2015). The Story of the ILO's Promotion of Cooperatives Recommendation, 2002 (No.193): A review of the process of making ILO Recommendation No.193, its implementation and its impact. International Labour Organization, Geneva.

Internacional Co-operative Alliance. (2013, Jan). Plano de ação para uma década cooperativa. Retrieved Jul 05, 2017, from Internacional Co-operative Alliance: https://ica.coop/sites/default/files/publication-files/ica-blueprint-f inal-june-2013-portuguese-975329096.pdf

Internacional Co-operative Alliance. (2017). Retrieved maio 26, 2017, from The alliance: https:/ica.coop/en/inter national-co-operative-alliance 
International Co-operative Alliance. (2015). Guidance Notes to the Co-operative Principles. International Co-operative Alliance, Bruxelas.

Irion, J. (1997). Cooperativismo e economia social. São Paulo: STS.

Johnson, M., Morgeson, F., \& Hekman, D. (2012, Nov.). Cognitive and affective identification: Exploring the links between different forms of social identification and personality with work attitudes and behavior. Journal of Organizational Behavior, 33(8), 1142-1167.

Jones, C., \& Volpe, E. (2011). Organizational identification: extending our understanding of social identities through social networks. Journal of Organizational Behavior, 32, 413-434.

Kennedy, J., \& Anderson, C. (2017). Hierarchical rank and principled dissent: How holding higher rank suppresses objection to unethical practices. Organizational Behavior and Human Decision Processes, 139, 30-49.

Kinpara, D., \& Laros, J. (2014, Jan-Mar). Clima Organizacional: análise fatorial confirmatória de modelos de mensuração concorrentes. Psicologia: Teoria e Pesquisa, 30(1), 111-120.

Klein, K., \& Sorra, J. (1996). The Challenge of Innovation Implementation. Academy ot Managernent Review, 21(4), 1055-1080.

Kogut, B., \& Zander, U. (1996, September-October). What Firms Do? Coordination, Identity, and Learning. Organization Science, 7(5), 502-518.

Lambert, P. (1975). La Doctrina Cooperativa (4. ed.). Buenos Aires: Intercoop.

Lasserre, G. (1977). O cooperativismo. Sintra: Europam.

Luz, R. (2003). Gestão do Clima Organizacional: proposta de critérios para metodologia de diagnóstico, mensuração e mehoria. Estudo de Caso em organizaçôes nacionais e multinacionais localizadas na cidade do Rio de Janeiro. Dissertação apresentada ao Curso de Mestrado em Sistemas de Gestão, Universidade Federal Fluminense, Niterói.

Maciel, G. (2011). Análise do Clima Organizacional de uma Agência Bancária de Curitiba - PR. Trabalho de Conclusão de Curso apresentado ao Curso de Especialiazação em Gestão de Negócios Financeiros, Universidade Federal do Rio Grande do Sul, Porto Alegre.

Mael, F., \& Ashforth, B. (1992, Mar). Alumni and their alma mater: a partial test of the reformulated model of organizational identification. Journal of Organizational Behavior, 13, 103-123.

Marra, A., Fonseca, J., \& Marques, A. (2014, Jan-Fev). O processo de identificação organizacional ante a reforma administrativa. Revista de Administração da Mackenzie, 15 (1), 49-72.

Martins, M. (2008). Clima organizacional. In M. Siqueira, Medidas do Comportamento Organizacional: Ferramentas de Diagnóstico e de Gestão. Porto Alegre: Artmed.

Meinen, Ê., \& Port, M. (2014). Cooperativismo financeiro, percurso histórico, perspectivas e desafios: De cooperativa de crédito a principal instituição financeira do associado (1. ed.). Brasília: Confebras.

Menéndez, F., Peña-Suárez, E., Fonseca-Pedrero, E., \& Muñiz, J. (2017, jan). Computerized Adaptive Assessment of Organizational Climate. Anales de Psicología, 33(1), 152-159.

Menezes, I., \& Gomes, A. (2010, abr). Clima organizacional: uma revisão histórica do construto. Psicologia em Revista, 16(1), 158-179.

Moran, E., \& Volkwein, J. (1992, Jan). The cultural approach to the formation of organizational climate. Human Relations, 45(1), 19-47.

Moreira, M., Bizarria, F., Lima, A., \& Moreira, A. (2016, set-dez). Fatores determinantes da identificação organizacional no contexto industrial. Perspectivas Contemporâneas, 11(3), 116-139.

Mourão, L., Monteiro, A., \& Viana, V. (2014, abr-jun). A influência do desenvolvimento profissional e da identificação organizacional na satisfação no trabalho. Psico, 45(2), 198-208.

Muñiz, J., Peña-Suárez, E., de la Roca, Y., Fonseca-Pedrero, E., Cabal, Á., \& García-Cueto, E. (2014, May). Organizational climate in Spanish Public Health Services: Administration and Services Staff. International Journal of Clinical and Health Psychology, 14(2), 102-110. 
Nelson, T., Nelson, D., Huybrechts, B., Dufays, F., O’Shea, N., \& Trasciani, G. (2016, may). Emergent identity formation and the cooperative: theory building in relation to alternative organizational forms. Entrepreneurship \& Regional Development, 28(3-4), 286-309.

Novaes, T. C. (2018). Gestão por Propósito: Como ela pode influenciar no resultado e na eficiência cooperativista de uma cooperativa de crédito. Universidade do Vale do Rio dos Sinos, São Leopoldo.

OCERGS-SESCOOP/RS. (2017). Expressäo do Cooperativismo Gaúcho 2016. Sistema Ocergs-Sescoop/RS, Porto Alegre.

Oliveira, Á. (2008). Identificação Organizacional. In M. Siqueira, Medidas do comportamento organizacional: ferramentas de diagnóstico e de gestão ( $1^{\mathrm{a}}$ ed., p. 344). Porto Alegre: Artmed.

Organização das Cooperativas Brasileiras. (2016). OCB. Retrieved setembro 04, 2016, from http://www.ocb.org.br/ site/ocb/index.asp?CodIdioma $=1$

Ostroff, C. (1993, Oct). The effects of climate and personal influences on individual behavior and attitudes in organizations. Organizational Behavior and Human Decision Processes, 56(1), 56-90.

Paré, A. (2009). Intercooperação: a formação de redes flexiveis como estratégia competitiva inteligente. Porto Alegre: Sescoop/RS.

Parolin, S., \& Albuquerque, L. (2011, jan./abr.). Gestão estratégica de pessoas para a inovação: o caso da Frimesa Cooperativa Central. Revista de Administração da UFSM, 4(1), 105-124.

Peña-Suárez, E., Muñiz, J., Campillo-Álvarez, Á., Fonseca-Pedrero, E., \& García-Cueto, E. (2013). Assessing organizational climate: psychometric properties of the CLIOR scale. Psicothema 2013, 25(1), 137-144.

Pena-Viveros, R., Hernandez-Hernandez, D., Velez-Moreno, A., Garcia-Sandoval, M., Reyes-Tellez, M., \& UrenaBogarin, E. (2015, Nov-Dez). Organizational climate in management teams and its relationship with health care outcomes. Salud Publica de Mexico, 57(6), 528-536.

Pinho, D. (1966). Que é cooperativismo. São Paulo: DESA.

Pinho, D. (2004). O Cooperativismo no Brasil: da vertente pioneira à vertente solidária. São Paulo: Saraiva.

Polônio, W. (1999). Manual das sociedades cooperativas (2. ed.). São Paulo: Atlas.

Portal do Cooperativismo Brasileiro. (2016). Cooperativismo. Retrieved Setembro 17, 2017, from História do Cooperativismo de Crédito no Brasil: http://cooperativismodecredito.coop.br/cooperativismo/historia-do-co operativismo/historia-no-brasil/

Portal do Cooperativismo de Crédito. (2016). Cenário Mundial. Retrieved jan. 07, 2018, from Cenário Brasileiro: h ttp://cooperativismodecredito.coop.br/cenario-mundial/cenario-brasileiro/

Portal do Cooperativismo de Crédito. (2017). Cenário Mundial. Cenário Brasileiro. Dados consolidados dos Sistemas Cooperativos. Retrieved jan. 20, 2018, from Sistema Sicredi: http://cooperativismodecredito.coop.br/cenario-m undial/cenario-brasileiro/dados-consolidados-dos-sistemas-cooperativos/sistema-sicredi/

Portal do Cooperativismo de Crédito. (2017). Cooperativismo Financeiro no Brasil. Retrieved 12 01, 2017, from Conheça as maiores instituições financeiras cooperativas do Brasil: http://cooperativismodecredito.coop.br/20 17/05/conheca-as-maiores-instituicoes-financeiras-cooperativas-do-brasil/

Portal do Cooperativismo Financeiro. (2018). Cenário Mundial. Cenário Brasileiro. Dados consolidados dos Sistemas Cooperativos. Retrieved 06 27, 2019, from Sistema Sicredi: https://cooperativismodecredito.coop.br/cenario-m undial/cenario-brasileiro/dados-consolidados-dos-sistemas-cooperativos/sistema-sicredi/

Puente-Palacios, K. (2002, jul-set). Abordagens teóricas e dimensões empíricas do conceito de clima organizacional. Revista de Administração, 37(3), 96-104.

Puente-Palacios, K., \& Freitas, I. (2006, Set). Clima Organizacional: uma análise de sua definição e de seus componentes. Organizaçôes \& Sociedade, 13(38), 45-57.

Ravasi, D., \& Schultz, M. (2006). Responding to Organizational Identity Threats: Exploring the Role of Organizational Culture. Academy of Management Journal, 49(3), 433-458.

Rossi, A. (2005). Cooperativismo à luz dos princípios constitucionais. Curitiba: Juruá. 
Santos, A., Gouveia, F. H., \& Vieira, P. S. (2012). Contabilidade das sociedades cooperativas: aspectos gerais e prestação de contas (2. ed.). São Paulo: Atlas.

Santos, J. (2012). Clima organizacional na administração pública: análise do conceito nos termos de referência dos editais de licitação no Brasil para o fortalecimento do processo de gestão. XVII Congreso Internacional del CLAD sobre la Reforma del Estado y de la Administración Pública, (pp. 1-17). Cartagena.

Santos, J., Macêdo, N., Gadelha, M., Ramalho, Â., \& Silva, S. (2010). Clima Organizacional: um estudo de caso em uma empresa varejista em Campina Grande - PB. VII SEGeT - Simpósio de Excelência em Gestão e Tecnologia, (pp. 1-16). Resende.

Schein, E. H. (2009). Cultura organizacional e liderança. São Paulo: Atlas.

Schneider, J. O. (2012, Jul-Dez). A Doutrina do Cooperativismo: análise do alcance, do sentido e da atualidade dos seus Valores, Princípios e Normas nos tempos atuais. Cadernos de Gestão Social, 3(2), 251-273.

Schneider, B., \& Reichers, A. (1983). On the etiology of climates. Personnel psychology, 36(1), 19-39.

Schneider, B., White, S., \& Paul, M. (1998). Linking Service Climate and Customer Perceptions of Service Quality: Test of a Causal Model. Journal of Applied Psychology, 83(2), 150-163.

Scott, S., \& Bruce, R. (1994, Jun). Determinants of Innovative Behavior: A Path Model of Individual Innovation in the Workplace. The Academy of Management Journal, 37(3), 580-607.

Sicredi Região Centro. (2016). Relatório Social. Sicredi Região Centro, Santa Maria. Retrieved 08 01, 2018, from htt ps://www.sicrediregiaocentro.coop.br/assembleias/relatorio-anual

Sicredi Região Centro RS/MG. (2018). Estatuto Social da Cooperativa de Crédito, Poupança e Investimento das Regiões Centro do RS e MG. Santa Maria.

Sicredi Região Centro RS/MG. (2019). Institucional. Retrieved Maio 22, 2019, from Missão e Valores: https://www .sicrediregiaocentro.coop.br/institucional/missao-e-valores

Sicredi Serrana RS. (2019a). Institucional. Retrieved jun 26, 2019, from História da Sicredi Serrana RS: http://www .sicrediserranars.com.br/institucional/historia-da-sicredi-serrana-rs

Sicredi Serrana RS. (2019b). Institucional. Retrieved jun 26, 2019, from Propósito e Valores: http://www.sicrediserr anars.com.br/institucional/proposito-e-valores

Sicredi União RS. (2019). A Cooperativa. Retrieved jun 28, 2019, from Linha do Tempo: https://sicrediuniaors.co m.br/linha-tempo

Sistema OCB. (2016). Agenda Institucional do Cooperativismo. Sistema OCB - Gerência de Relações Institucionais. Brasília: OCB.

Sistema OCB. (2017a). Agenda Institucional do Cooperativismo. Sistema OCB - Gerência de Relações Institucionais, Brasília.

Sistema OCB. (2017b). Cooperativismo. O que é Cooperativismo. Retrieved 05 30, 2017, from Sistema OCB: http:// www.ocb.org.br/\#/o-que-e-cooperativismo

Sistema OCB. (2018). Números do Cooperaivismo Brasileiro. Retrieved Outubro 18, 2019, from Sistema OCB: http s://www.ocb.org.br/numeros

Sistema OCB. (2019). Ramos do Cooperativismo: conheça nossa nova organização. Retrieved Outubro 18, 2019, from Sistema OCB: https://somoscooperativismo.coop.br/publicacao/57/ramos-do-cooperativismo

Slater, S., \& Narver, J. (1995, Jul). Marketing Orientation and the Learning Organization. Journal of Marketing, 63-74.

Smith, L., Gillespie, N., Callan, V., Fitzsimmons, T., \& Paulsen, N. (2017). Injunctive and descriptive logics during newcomer socialization: the impact on organizational identification, trustworthiness, and self-efficacy. Journal of Organizational Behavior, 38, 487-511.

Souza, L. (2017). Cooperativas de crédito: regulação do CMN e os valores cooperativos. Curitiba: Juruá.

Stecca, J. (2014). Estratégias genéricas na gestão de pessoas e comprometimento organizacional: um estudo em sociedades cooperativas de crédito. FEA / USP, São Paulo.

Stecca, J., Stecca, F., Bento, M., \& Rossés, G. (2016, Jan./Jun.). Diagnóstico de Clima Organizacional em uma Cooperativa de Crédito. Revista Gesto, 4(1), 43-53. 
Stoner, J., Perrewe, P., \& Hofacker, C. (2011). The Development and Validation of the Multi-Dimensional Identification Scale (MDIS). Journal of Applied Social Psychology, 41(7), 1632-1658.

Telles, R. (2001, out./dez.). A efetividade da matriz de amarração de Mazzon nas pesquisas em Administração. Revista de Administração, 36(4), 64-72.

Thomaz, J., \& Brito, E. (2010, Mar-Abr). Reputação corporativa: construtos formativos e implicações para a gestão. $R A C, 14(2), 229-250$.

Thumin, F., \& Thumin, L. (2011). The Measurement and Interpretation of Organizational Climate. The Journal of Psychology: Interdisciplinary and Applied, 145(2), 93-109.

Tortorella, G., Escobar, L., \& Rodrigues, C. (2015). Organizational climate research: a proposed approach focused on banking institutions. Business Process Management Journal, 21(6), 1377-1390.

Tsui, A., Egan, T., \& O'Reilly III, C. (1992, December). Being Different: relational demography and organizational attachment. Administrative Science Quarterly, 37(4), 549-579.

Vergara, S. (2016). rojetos e Relatórios de Pesquisa em Administração (16a ed.). São Paulo: Atlas.

Walumbwa, F., Mayer, D., Wang, P., Wang, H., Workman, K., \& Christensen, A. (2011). Linking ethical leadership to employee performance: The roles of leader-member exchange, self-efficacy, and organizational identification. Organizational Behavior and Human Decision Processes, 115, 204-213.

Weick, K., Sutcliffe, K., \& Obstfe, D. (2005, Jul-Ago). Organizing and the Process of Sensemaking. Organization Science, 16(4), 409-421.

Wilhelm, E., \& Schneider, J. (2013). O Primeiro centenário de um sonho (Vol. 1.). Santa Rosa: Edição do Autor.

WOS. (2017). Retrieved 06 29, 2017, from Web Of Science: http://apps.webofknowledge.com/Search.do?product= WOS\&SID=4BwPj8R6I61Mq15pa7N\&search_mode=GeneralSearch\&prID=ef326608-ef29-421d-98ec-55 $7 \mathrm{f} 3 \mathrm{f5} \mathrm{d} 496 \mathrm{a}$

WOS. (2017b). Retrieved 07 06, 2017, from Web OfScience: http://apps-webofknowledge.ez47.periodicos.capes.gov .br/Search.do?product $=$ WOS\&SID=7Exw2CbDXLuJfDtghNs\&search_mode=GeneralSearch\&prID=74e8 b84d-e474-48c7-95ca-3274b098e960

WOS. (2018a). Retrieved 01 21, 2018, from Web OfScience: http://apps-webofknowledge.ez47.periodicos.capes.gov. $\mathrm{br} /$ summary.do?product $=$ WOS\&parentProduct $=$ WOS\&search_mode $=$ GeneralSearch\&parentQid $=\& q i d=$ 33\&SID=6AjdsElwRPG99w815zY\&\&update_back2search_link_param=yes\&page=2

WOS. (2018b). Retrieved 0427,2018, from Web OfScience: http://apps.webofknowledge.com/Search.do?product= WOS\&SID=4BwPj8R6161Mq15pa7N\&search_mode=GeneralSearch\&prID=ef326608-ef29-421d-98ec-55 $7 \mathrm{f} 3 \mathrm{f} 5 \mathrm{~d} 496 \mathrm{a}$ 